\title{
AN INTEGRATED INTUITIONISTIC FUZZY MULTI CRITERIA DECISION MAKING METHOD FOR FACILITY LOCATION SELECTION
}

\author{
Fatih Emre Boran \\ Department of Industrial Engineering, \\ Atilim University, 06836, Golbasi, Ankara, Turkey \\ feboran@atilim.edu.tr
}

\begin{abstract}
The facility location selection, which is one of the important activities in strategic planning for a wide range of private and public companies, is a multi-criteria decision making problem including both quantitative and qualitative criteria. Traditional methods for facility location selection can not be effectively handled because information can not be represented by precise information under many conditions. This paper proposes the integration of intuitionistic fuzzy preference relation aiming to obtain weights of criteria and intuitionistic fuzzy TOPSIS (Technique for Order Preference by Similarity to Ideal Solution) method aiming to rank alternatives for dealing with imprecise information on selecting the most desirable facility location. To illustrate the application of the proposed method, a practical application is given.
\end{abstract}

Key Words- Facility location selection, Multi criteria decision making, Intuitionistic fuzzy set, Intuitionistic fuzzy preference relation, Intuitionistic fuzzy TOPSIS method

\section{INTRODUCTION}

Today's fierce competitive environment enforces companies to make right decisions on management activities. Perhaps, one of the most important decisions for companies is facility location selection, since it is a costly and difficult to reserve activity. Facility location selection has a great impact on output of operating and management activities in companies [1]. A poor choice of location might result in unnecessary transportation costs, a lack of qualified labor, lost of competitive advantage, insufficient supplies of raw materials, or some similar conditions that would be detrimental to operations [2]. On the other hand, a good choice of location might result in some advantages such as decrease in transportation cost, maximizing the usage of resources, higher logistic performance and efficiency in operations for companies.

Facility location selection is a typical multi-criteria decision making problem including conflicting criteria such as political environment, proximity to markets and customers, supplier networks, expansion potential, availability of transportation systems and utility, quality-of-life issues, culture issues, etc. $[3,4]$. The majority of these attributes are evaluated with human perceptions and judgments which cannot be quantified precisely [5] and therefore, involves the imprecision and vagueness inherent in linguistic assessment and fuzzy multiple attributes decision-making (FMADM) [6].

There are large numbers of methods that have been developed for the facility location selection. Fuzzy set theory (FST) has been applied in the recent studies to deal with selecting facility location with respect to subjective factors. Liang and Wang [7] developed an algorithm based on FST and hierarchical structure in order to deal with selecting facility location. Kuo et al. [8] proposed a decision support system (DSS) based on FST and the analytic hierarchy process (AHP) to select a site for a new 
convenience store (CVS). Kuo et al. [9] developed a DSS to select location of new CVSs by combining fuzzy AHP and artificial neural network. Chen [10] developed a new approach based on FMADM with a stepwise ranking procedure to resolve the selection of distribution center location under fuzzy environment. Chu [11] proposed fuzzy TOPSIS model for facility location selection. Kahraman et al. [12] presented four fuzzy multi-attribute group decision-making approaches for evaluating facility locations. Cou et al. [6] applied fuzzy simple additive weighting method for facility location selection with objective and subjective factors. Kapoor et al. [13] used fuzzy CMeans clustering algorithm to select appropriate facility location. There are four well known methods are commonly used in the facility location selection; factor rating system, break-even analysis, center of gravity method and transportation method $[12,14,15]$.

This paper proposes an intuitionistic fuzzy multi-criteria decision making method with the TOPSIS (Technique for Order Preference by Similarity to Ideal Solution) method for selecting facility location. The TOPSIS method considering positive and negative ideal solution is one of the most popular methods in multi-criteria decision making [16] and applied some decision problems [17-19]. On the other hand, the impact of alternatives on criteria provided by decision makers is usually difficult to be precisely expressed by the crisp data in the facility location selection. Intuitionistic fuzzy sets introduced by Atanassov [20], is the extension of fuzzy sets introduced by Zadeh [21]. An intuitionistic fuzzy set is characterized by three parameters: membership function, non-membership function and hesitation margin namely, which is a flexible way to deal with uncertainty, while a fuzzy set is only characterized by membership function.

The rest of this paper is organized as follows. In the next section, brief descriptions on intuitionistic fuzzy set are given. Section 3 gives a detailed description of the proposed method. A practical application is given to illustrate the application of the proposed method in Section 4. Finally, conclusions of the paper are presented.

\section{INTUITIONISTIC FUZZY SETS}

In this section, definitions of intuitionistic fuzzy set related to this study are given.

Definition 1. [20] An intuitionistic fuzzy set $A$ in a finite set $X$ can be written as:

$$
A=\left\{\left\langle x, \mu_{A}(x), v_{A}(x)\right\rangle \mid x \in X\right\}
$$

where $\mu_{A}(x): X \rightarrow[0,1]$ and $v_{A}(x): X \rightarrow[0,1]$ are membership function and nonmembership function respectively, such that:

$$
0 \leq \mu_{A}(x)+v_{A}(x) \leq 1
$$

The third parameter of the IFS $A$ is:

$$
\pi_{A}(x)=1-\mu_{A}(x)-v_{A}(x)
$$

which is known as the intuitionistic fuzzy index or hesitation degree of whether $x$ belongs to $A$ or not.

It is obviously seen that for every $x \in X$ : 


$$
0 \leq \pi_{A}(x) \leq 1
$$

If the $\pi_{A}(x)$ is small, then knowledge about $x$ is more certain; if $\pi_{A}(x)$ is great, then knowledge about $x$ is more uncertain. Obviously, when $\mu_{A}(x)=1-v_{A}(x)$, for all elements of the universe, the traditional fuzzy set concept is recovered [22].

Definition 2. Let $A$ and $B$ IFSs in defined as:

$$
\begin{aligned}
& A=\left\{\left\langle x, \mu_{A}(x), v_{A}(x)\right\rangle \mid x \in X\right\} \\
& B=\left\{\left\langle x, \mu_{B}(x), v_{B}(x)\right\rangle \mid x \in X\right\}
\end{aligned}
$$

Hamming distance between IFSs $A$ and $B$ is given as follows:

$$
d(A, B)=\frac{1}{2}\left[\left|\mu_{A}(x)-\mu_{B}(x)\right|+\left|v_{A}(x)-v_{B}(x)\right|+\left|\pi_{A}(x)-\pi_{B}(x)\right|\right]
$$

\section{AN INTEGRATED INTUITIONISTIC FUZZY MULTI-CRITERIA DECISION-MAKING METHOD}

In this section, the TOPSIS method is extended to intuitionistic fuzzy environment, which is a very suitable for solving decision-making problems.

Let $A=\left\{A_{1}, A_{2}, \ldots, A_{m}\right\}$ be a set of alternatives $C=\left\{C_{1}, C_{2}, \ldots, C_{n}\right\}$ be a set of criteria. Intutionistic fuzzy TOPSIS method consists of the following steps which are given as follows:

Step 1. Construct an intuitionistic fuzzy preference relation matrix:

Let $B=\left(b_{i j}\right)_{n x n}$ be an intuitionistic preference matrix of criteria as follows:

$$
B=\left[\begin{array}{ccccc}
\tilde{b}_{11} & \tilde{b}_{12} & \tilde{b}_{13} & \ldots & \tilde{b}_{1 n} \\
\tilde{b}_{21} & \tilde{b}_{22} & \tilde{b}_{23} & \ldots & \tilde{b}_{2 n} \\
\tilde{b}_{31} & \tilde{b}_{32} & \tilde{b}_{33} & \ldots & \tilde{b}_{3 n} \\
\vdots & \vdots & \vdots & \ddots & \vdots \\
\tilde{b}_{m 1} & \tilde{b}_{m 2} & \tilde{b}_{m 3} & \ldots & \tilde{b}_{m n}
\end{array}\right]
$$

where $\tilde{b}_{i j}=\left(\mu_{i j}, v_{i j}\right) \quad(i=1,2 \ldots, n ; j=1,2, \ldots, n)$

and satisfies the following condition $[23,24]$ :

$$
\begin{gathered}
\left(\mu_{i j}\right)^{*}=\max \left\{\mu_{i j}, \max _{p}\left\{\frac{\mu_{i p} \mu_{p j}}{\mu_{i p} \mu_{p j}+\left(1-\mu_{i p}\right)\left(1-\mu_{p j}\right)}\right\}\right\} \\
\left(v_{i j}\right)^{*}=\max \left\{v_{i j}, \max _{p}\left\{\frac{v_{i p} v_{p j}}{v_{i p} v_{p j}+\left(1-v_{i p}\right)\left(1-v_{p j}\right)}\right\}\right\}
\end{gathered}
$$

where $\left(\mu_{i j}\right)^{*}$ and $\left(v_{i j}\right)^{*}$, the element of $(B)^{*}$ matrix, are the membership degree and the non-membership degree of the alternative $x_{i}$ over $x_{j}$, respectively, and 
$0 \leq\left(\mu_{i j}\right)^{*}+\left(v_{i j}\right)^{*} \leq 1$ for all $i, j, k=1,2, \ldots, n$, then we call $B$ a multiplicative consistent intuitionistic fuzzy preference relation. If $(B)^{*}=\left(b_{i j}\right)_{n x n}^{*}$ does not satisfy the condition $0 \leq\left(\mu_{i j}\right)^{*}+\left(v_{i j}\right)^{*} \leq 1$ for any $i, j=1,2, \ldots, n$, then we call $B$ an inconsistent intuitionistic fuzzy preference relation.

Step 2. Obtain the priority vector of criteria:

After obtained aggregated intuitionistic fuzzy preference matrix, the priority vector of criteria $w=\left(w_{1}, w_{2}, \ldots, w_{n}\right)^{\mathrm{T}}$ can be estimated with the following equation proposed by Genç et al. [23,24]:

$$
w_{j}=\left[w_{j}^{L}, w_{j}^{U}\right]=\left(\frac{1}{\sum_{j=1}^{n}\left(\frac{\left(1-\tilde{\mu}_{i j}^{*}\right)}{\tilde{\mu}_{i j}^{*}}\right)}, \frac{1}{\sum_{j=1}^{n}\left(\frac{\tilde{v}_{i j}^{*}}{\left(1-\tilde{v}_{i j}^{*}\right)}\right)}\right)
$$

Step 3. Construct an intuitionistic fuzzy decision matrix:

$\tilde{R}=\left(\tilde{r}_{i j}\right)_{m x n}$ is an intuitionistic fuzzy decision matrix such that:

$$
\tilde{R}=\left[\begin{array}{ccccc}
\tilde{r}_{11} & \tilde{r}_{12} & \tilde{r}_{13} & \ldots & \tilde{r}_{1 n} \\
\tilde{r}_{21} & \tilde{r}_{22} & \tilde{r}_{23} & \ldots & \tilde{r}_{2 n} \\
\tilde{r}_{31} & \tilde{r}_{32} & \tilde{r}_{33} & \ldots & \tilde{r}_{3 n} \\
\vdots & \vdots & \vdots & \ddots & \vdots \\
\tilde{r}_{m 1} & \tilde{r}_{m 2} & \tilde{r}_{m 3} & \ldots & \tilde{r}_{m n}
\end{array}\right]
$$

where $\quad \tilde{r}_{i j}=\left(\mu_{i j}, v_{i j}, \pi_{i j}\right) \quad(i=1,2 \ldots, m ; j=1,2, \ldots, n)$, which are contained in an intuitionistic fuzzy decision matrix.

Step 4. Determine the intuitionistic fuzzy positive ideal solution and the intuitionistic fuzzy negative ideal solution:

Let $J_{1}$ be the set of benefit criteria, $J_{2}$ be the set of cost criteria, $A^{*}$ be the intuitionistic fuzzy positive ideal solution, and $A^{-}$be the intuitionistic fuzzy negative ideal solution, then $A^{*}$ and $A^{-}$can be determined respectively as:

$$
\begin{gathered}
A^{*}=\left(\tilde{r}_{1}^{*}, \tilde{r}_{2}^{*}, \ldots, \tilde{r}_{n}^{*}\right), \tilde{r}_{j}^{*}=\left(\mu_{j}^{*}, v_{j}^{*}, \pi_{j}^{*}\right), j=1,2, \ldots, n \\
A^{-}=\left(\tilde{r}_{1}^{-}, \tilde{r}_{2}^{-}, \ldots, \tilde{r}_{n}^{-}\right), \tilde{r}_{j}^{-}=\left(\mu_{j}^{-}, v_{j}^{-}, \pi_{j}^{-}\right), j=1,2, \ldots, n
\end{gathered}
$$

where

$$
\begin{aligned}
& \mu_{j}^{*}=\left\{\left(\max _{i}\left\{\mu_{i j}\right\} \mid j \in J_{1}\right),\left(\min _{i}\left\{\mu_{i j}\right\} \mid j \in J_{2}\right)\right\} \\
& v_{j}^{*}=\left\{\left(\min _{i}\left\{v_{i j}\right\} \mid j \in J_{1}\right),\left(\max _{i}\left\{v_{i j}\right\} \mid j \in J_{2}\right)\right\} \\
& \mu_{j}^{-}=\left\{\left(\min _{i}\left\{\mu_{i j}\right\} \mid j \in J_{1}\right),\left(\max _{i}\left\{\mu_{i j}\right\} \mid j \in J_{2}\right)\right\}
\end{aligned}
$$




$$
\begin{gathered}
v_{j}^{-}=\left\{\left(\max _{i}\left\{v_{i j}\right\} \mid j \in J_{1}\right),\left(\min _{i}\left\{v_{i j}\right\} \mid j \in J_{2}\right)\right\} \\
\pi_{j}^{*}=\left\{\left(1-\max _{i}\left\{\mu_{i j}\right\}-\min _{i}\left\{v_{i j}\right\} \mid j \in J_{1}\right),\left(1-\min _{i}\left\{\mu_{i j}\right\}-\max _{i}\left\{v_{i j}\right\} \mid j \in J_{2}\right)\right\} \\
\pi_{j}^{-}=\left\{\left(1-\min _{i}\left\{\mu_{i j}\right\}-\max _{i}\left\{v_{i j}\right\} \mid j \in J_{1}\right),\left(1-\max _{i}\left\{\mu_{i j}\right\}-\min _{i}\left\{v_{i j}\right\} \mid j \in J_{2}\right)\right\}
\end{gathered}
$$

Step 5. Calculate the weighted separation measures:

The weighted Hamming distance is used to obtain separation measures [25,26]. The weighted lower and upper separation measures $\left(S_{i}^{*}\right)^{L},\left(S_{i}^{*}\right)^{U}$ and $\left(S_{i}^{-}\right)^{L},\left(S_{i}^{-}\right)^{U}$ of each alternative from the intuitionistic fuzzy positive ideal solution and the intuitionistic fuzzy negative ideal solution are respectively calculated:

$$
\begin{aligned}
& \left(S_{i}^{*}\right)^{L}=\frac{1}{2} \sum_{j=1}^{n} w_{j}^{L}\left[\left|\mu_{i j}-\mu_{j}^{*}\right|+\left|v_{i j}-v_{j}^{*}\right|+\left|\pi_{i j}-\pi_{j}^{*}\right|\right] \\
& \left(S_{i}^{*}\right)^{U}=\frac{1}{2} \sum_{j=1}^{n} w_{j}^{U}\left[\left|\mu_{i j}-\mu_{j}^{*}\right|+\left|v_{i j}-v_{j}^{*}\right|+\left|\pi_{i j}-\pi_{j}^{*}\right|\right] \\
& \left(S_{i}^{-}\right)^{L}=\frac{1}{2} \sum_{j=1}^{n} w_{j}^{L}\left[\left|\mu_{i j}-\mu_{j}^{-}\right|+\left|v_{i j}-v_{j}^{-}\right|+\left|\pi_{i j}-\pi_{j}^{-}\right|\right] \\
& \left(S_{i}^{-}\right)^{U}=\frac{1}{2} \sum_{j=1}^{n} w_{j}^{U}\left[\left|\mu_{i j}-\mu_{j}^{-}\right|+\left|v_{i j}-v_{j}^{-}\right|+\left|\pi_{i j}-\pi_{j}^{-}\right|\right]
\end{aligned}
$$

Step 6. Calculate the relative closeness coefficient of each alternative to the intuitionistic fuzzy positive and the negative ideal solutions:

The relative closeness coefficient of an alternative $A_{i}$ with respect to the intuitionistic fuzzy positive-ideal solution $A^{*}$ and the intuitionistic fuzzy negative-ideal solution $A^{-}$ is defined as follows:

$$
\left(\left(C_{i}^{*}\right)^{L},\left(C_{i}^{*}\right)^{U}\right)=\left\{\left(\frac{\left(S_{i}^{-}\right)^{L}}{\left(S_{i}^{*}\right)^{U}+\left(S_{i}^{-}\right)^{U}}\right),\left(\frac{\left(S_{i}^{-}\right)^{U}}{\left(S_{i}^{*}\right)^{L}+\left(S_{i}^{-}\right)^{L}}\right)\right\}
$$

Step 7. Rank the alternatives according to the descending order of the relative closeness coefficients $C_{i}^{*}=\left(\left(C_{i}^{*}\right)^{L},\left(C_{i}^{*}\right)^{U}\right)$.

In order to rank alternatives, the possibility degree formula proposed by $\mathrm{Xu}$ and $\mathrm{Da}$ [27] is used.

Definition 3. [27] Let $a=\left[a^{L}, a^{U}\right]$ and $b=\left[b^{L}, b^{U}\right]$ be two interval numbers where is $0 \leq a^{L} \leq a^{U} \leq 1$ and $0 \leq b^{L} \leq b^{U} \leq 1$ then the degree of possibility of $a \geq b$ is defined as:

$$
p(a \geq b)=\max \left\{1-\max \left(\frac{b^{U}-a^{L}}{b^{U}-b^{L}+a^{U}-a^{L}}, 0\right), 0\right\}
$$

that is $a$ superior to $b$ to degree of, donated by $a \stackrel{p(a \geq b)}{\succ} b$. 
Similarly, the degree of possibility of $b \geq a$ is defined as:

$$
p(b \geq a)=\max \left\{1-\max \left(\frac{a^{U}-b^{L}}{b^{U}-b^{L}+a^{U}-a^{L}}, 0\right), 0\right\}
$$

that is $b a$ superior to $a$ to degree of, donated by $b \stackrel{p(b \geq a)}{\succ} a$.

Let be $p_{i j}=p\left(a_{i} \geq a_{j}\right)$ complementary matrix and given as follows:

where $p_{i j} \geq 0, p_{i j}+p_{j i}=1, p_{i i}=0.5$ and $i, j=1,2,3, \ldots n$

$$
P=\left[\begin{array}{ccccc}
p_{11} & \tilde{r}_{12} & \tilde{r}_{13} & \cdots & p_{1 n} \\
p_{21} & p_{22} & p_{23} & \cdots & p_{2 n} \\
p_{31} & p_{32} & p_{33} & \cdots & p_{3 n} \\
\vdots & \vdots & \vdots & \ddots & \vdots \\
p_{n 1} & p_{n 2} & p_{n 3} & \cdots & p_{n n}
\end{array}\right]
$$

Summing all elements in each line of matrix $P$, then:

$$
p_{i}=\sum_{j=1}^{n} p_{i j} i, j=1,2,3, \ldots, n
$$

Alternatives are ranked according to descending order of $p_{i}$.

\section{PRACTICAL APPLICATION}

A manufacturing company is select to location for building new plant. There are four candidates place $A_{1}, A_{2}, A_{3}$ and $A_{4}$ are chosen for further evaluation. In order to evaluate candidate locations, expansion possibility $\left(\mathrm{C}_{1}\right)$, availability of acquirement material $\left(\mathrm{C}_{2}\right)$, community considerations $\left(\mathrm{C}_{3}\right)$, distance to market $\left(\mathrm{C}_{4}\right)$ and labour cost $\left(\mathrm{C}_{5}\right)$ are considered as evaluation factors.

Step 1. Construct an intuitionistic fuzzy preference relation matrix.

Let $B=\left(b_{i j}\right)_{5 \times 5}$ be an intuitionistic preference matrix of criteria

$$
B=\left[\begin{array}{ccccc}
(0.50,0.50) & (0.60,0.30) & (0.70,0.20) & (0.60,0.35) & (0.55,0.35) \\
(0.30,0.60) & (0.50,0.50) & (0.50,0.45) & (0.30,0.60) & (0.30,0.60) \\
(0.20,0.70) & (0.45,0.50) & (0.50,0.50) & (0.25,0.65) & (0.25,0.70) \\
(0.35,0.60) & (0.60,0.30) & (0.65,0.25) & (0.50,0.50) & (0.40,0.50) \\
(0.35,0.55) & (0.60,0.30) & (0.70,0.25) & (0.50,0.40) & (0.50,0.50)
\end{array}\right]
$$

$B=\left(b_{i j}\right)_{5 x 5}$ has been the consistent intuitionistic preference matrix due to satisfying condition and the following matrices existing as follows: 


$$
B^{*}=\left[\begin{array}{lllll}
(0.50,0.50) & (0.69,0.30) & (0.74,0.26) & (0.60,0.39) & (0.55,0.39) \\
(0.30,0.69) & (0.50,0.50) & (0.50,0.45) & (0.39,0.60) & (0.34,0.66) \\
(0.26,0.74) & (0.45,0.50) & (0.50,0.50) & (0.27,0.65) & (0.26,0.70) \\
(0.39,0.60) & (0.60,0.39) & (0.65,0.27) & (0.50,0.50) & (0.40,0.50) \\
(0.39,0.55) & (0.66,0.34) & (0.70,0.26) & (0.50,0.40) & (0.50,0.50)
\end{array}\right]
$$

Step 2. Obtain the priority vector of criteria

The priority vector of criteria has been estimated by utilizing Eq. (10) as follows:

$$
\begin{gathered}
w_{1}=[0.305,0.326] w_{2}=[0.128,0.133] w_{3}=[0.094,0.111] \\
w_{4}=[0.190,0.221] w_{5}=[0.222,0.266]
\end{gathered}
$$

Step 3. Construct the intuitionistic fuzzy decision matrix.

The intuitionistic fuzzy decision matrix has been constructed in Table 1 as follows:

Table 1. The intuitionistic fuzzy decision matrix

\begin{tabular}{lccccc}
\hline \multirow{2}{*}{ Candidates } & \multicolumn{5}{c}{ Criteria } \\
\cline { 2 - 6 } & $\mathbf{C}_{\mathbf{1}}$ & $\mathbf{C}_{\mathbf{2}}$ & $\mathbf{C}_{\mathbf{3}}$ & $\mathbf{C}_{\mathbf{4}}$ & $\mathbf{C}_{\mathbf{5}}$ \\
\hline $\mathbf{A}_{\mathbf{1}}$ & $(0.74,0.16,0.10)$ & $(0.75,0.15,0.10)$ & $(0.73,0.21,0.06)$ & $(0.64,0.24,0.12)$ & $(0.56,0.28,0.16)$ \\
$\mathbf{A}_{\mathbf{2}}$ & $(0.82,0.08,0.10)$ & $(0.71,0.07,0.22)$ & $(0.78,0.12,0.10)$ & $(0.60,0.21,0.19)$ & $(0.62,0.26,0.12)$ \\
$\mathbf{A}_{\mathbf{3}}$ & $(0.78,0.13,0.09)$ & $(0.78,0.12,0.10)$ & $(0.71,0.18,0.11)$ & $(0.60,0.25,0.15)$ & $(0.58,0.24,0.18)$ \\
$\mathbf{A}_{\mathbf{4}}$ & $(0.76,0.18,0.06)$ & $(0.81,0.12,0.07)$ & $(0.68,0.17,0.15)$ & $(0.66,0.20,0.14)$ & $(0.52,0.35,0.13)$ \\
\hline
\end{tabular}

Step 4. Determine the intuitionistic fuzzy positive ideal solution and the intuitionistic fuzzy negative ideal solution.

Considering that expansion possibility, availability of acquirement material and community considerations are the benefit criteria, $J_{1}=\left\{C_{1}, C_{2}, C_{3}\right\}$, and distance to market and labour cost are the cost criterion $J_{2}=\left\{C_{4}, C_{5}\right\}$. Then the intuitionistic fuzzy positive and the intuitionistic fuzzy negative ideal solutions have been obtained by employing Eq.(11)-Eq.(18) as follows:

$$
\begin{aligned}
A^{*}= & \left.\begin{array}{l}
(0.82,0.08,0.10),(0.81,0.07,0.12),(0.78,0.12,0.10) \\
(0.60,0.25,0.15),(0.52,0.35,0.13)
\end{array}\right\} \\
A^{-}= & \begin{array}{l}
\frac{1}{1}(0.74,0.18,0.08),(0.71,0.15,0.14),(0.68,0.21,0.11) \dot{j} \\
\text { 亲 }(0.66,0.20,0.14),(0.62,0.24,0.14)
\end{array}
\end{aligned}
$$

Step 5. Calculate the weighted separation measures.

Negative and positive separation measures based on the weighted lower and upper Hamming distance for each candidate have been calculated by utilizing Eq.(19) -Eq.(22) and given in Table 2. 
Table 2. Separation measures of candidates

\begin{tabular}{lcccc}
\hline Candidates & $\left(S^{*}\right)^{L}$ & $\left(S^{*}\right)^{U}$ & $\left(S^{-}\right)^{L}$ & $\left(S^{-}\right)^{U}$ \\
\hline $\mathrm{A}_{1}$ & 0.066 & 0.074 & 0.037 & 0.042 \\
$\mathrm{~A}_{2}$ & 0.043 & 0.049 & 0.066 & 0.073 \\
$\mathrm{~A}_{3}$ & 0.053 & 0.060 & 0.047 & 0.053 \\
$\mathrm{~A}_{4}$ & 0.058 & 0.064 & 0.047 & 0.054 \\
\hline
\end{tabular}

Step 6. Calculate the relative closeness coefficient of each candidate to the intuitionistic fuzzy positive and negative ideal solutions.

The relative closeness coefficients of each candidate to the intuitionistic fuzzy positive and negative ideal solutions have been calculated by using Eq.(23) as follows:

$$
\begin{aligned}
& \left(\left(C_{1}^{*}\right)^{L},\left(C_{1}^{*}\right)^{U}\right)=\left\{\left(\frac{0.037}{0.074+0.042}\right),\left(\frac{0.042}{0.066+0.037}\right)\right\}=(0.319,0.408) \\
& \left(\left(C_{2}^{*}\right)^{L},\left(C_{2}^{*}\right)^{U}\right)=\left\{\left(\frac{0.066}{0.049+0.073}\right),\left(\frac{0.073}{0.043+0.066}\right)\right\}=(0.541,0.670) \\
& \left(\left(C_{3}^{*}\right)^{L},\left(C_{3}^{*}\right)^{U}\right)=\left\{\left(\frac{0.047}{0.060+0.053}\right),\left(\frac{0.053}{0.053+0.047}\right)\right\}=(0.416,0.530) \\
& \left(\left(C_{4}^{*}\right)^{L},\left(C_{4}^{*}\right)^{U}\right)=\left\{\left(\frac{0.047}{0.064+0.054}\right),\left(\frac{0.054}{0.058+0.047}\right)\right\}=(0.398,0.514)
\end{aligned}
$$

Step 7. Rank the candidates according to the descending order of the relative closeness coefficients.

Four candidate locations have been ranked according to the descending order of the relative closeness coefficients. The candidates have been ranked by using the possibility degree formula and the following matrix has been constructed as follows:

$$
P=\left[\begin{array}{cccc}
0.5 & 0 & 0 & 0.049 \\
1 & 0.5 & 1 & 1 \\
1 & 0 & 0.5 & 0.574 \\
0.951 & 0 & 0.426 & 0.5
\end{array}\right]
$$

Summing all elements in each line of matrix $P$, then:

$$
p_{1}=0.549 \quad p_{2}=3.5 \quad p_{3}=2.074 \quad p_{4}=1.877
$$

The candidates have been ranked as $A_{2} \mathrm{f} A_{3} \stackrel{0.574}{\mathrm{f}} A_{4} \stackrel{0.951}{\mathrm{f}} A_{1}$ according to descending order of $p_{i}(i=1,2,3,4)$. Thus, $A_{2}$ has been selected as the most desirable facility location among candidates.

\section{CONCLUSION}

The success of companies depends on their capability on making right strategic decisions. Facility location selection is one of these strategic decisions, which it is a costly and difficult to reverse activity for companies. Therefore, this paper has presented 
the integration of intuitionistic fuzzy preference relation and intuitionistic fuzzy TOPSIS method for selecting the most desirable facility location. The decision factors (attributes), expansion possibility, availability of acquirement material, community considerations, distance to market and labour cost have been taken into account and candidate locations have been evaluated by the proposed method with respect to the decision factors. The intuitionistic fuzzy preference relation has been applied to derive the weights of criteria and intuitionistic fuzzy TOPSIS method has been used to rank alternative. The integrated intuitionistic fuzzy multi criteria decision making method has enormous chances of success for multi-criteria decision making problems due to having great superiority on dealing with vagueness. Therefore, in the future, the proposed method can be used for dealing with uncertainty in a variety of multi-criteria decision making problems. Moreover, the proposed method may be extended to group decision environment and apply to important decision making problems. This is the issue for future researches.

\section{ACKNOWLEDGMENT}

The author is very grateful to the anonymous referees for their constructive comments and suggestions that led to an improved version of this paper.

\section{REFERENCES}

1. I. Ertugrul and N. Karakusoglu, Comparison of fuzzy AHP and fuzzy TOPSIS methods for facility location selection, The International Journal of Advanced Manufacturing Technology 39, 783-795, 2008.

2. W.J. Stevenson, Production / operations management, Homewood: 4th ed. Richard D. Irwin Inc., 1993.

3. J. J. Coyle, E. J. Bardi and C. J. Langley, The management of business logistics: A supply chain perspective, South-Western: Thomson, 2003.

4. C.Y. Shen and K.T. Yu, A generalized fuzzy approach for strategic problems: The empirical study on facility location selection of authors' management consultation client as an example, Expert Systems with Applications 36, 4709-4716, 2009.

5. A. J. Dubrin, Fundamentals of organizational behavior, South-Western: Thomson 2002.

6. S.Y. Chou, Y.H. Chang and C.Y. Shen, A fuzzy simple additive weighting system under group decision-making for facility location selection with objective/subjective attributes, European Journal of Operation Research 189,132$145,2008$.

7. G.S. Liang and M.J.J. Wang, A fuzzy multi-criteria decision-making method for facility site selection, International Journal of Production Research 29, 2313-2330, 1991.

8. R.J. Kuo, S.C. Chi and S.S. Kao, A decision support system for locating convenience store through fuzzy AHP, Computers \& Industrial Engineering 37, 323-326, 1999. 
9. R.J. Kuo, S.C. Chi and S.S. Kao, A decision support system for selecting convenience store location through integration of fuzzy AHP and artificial neural network, Computers in Industry 47,199-214, 2002.

10. C.T. Chen, A fuzzy approach to select the location of the distribution center, Fuzzy Sets and Systems 118, 65-73, 2001.

11. T.C. Chu, Facility location selection using fuzzy TOPSIS under group decisions, International Journal of Uncertainty, Fuzziness and Knowledge-Based Systems 10, 687-701, 2002.

12. C. Kahraman, D. Ruan and I. Dogan, Fuzzy group decision-making for facility location selection, Information Sciences 157, 135-153, 2003.

13. V. Kapoor, S.S. Tak and V.Sharma, Location Selection - A Fuzzy Clustering Approach, International Journal of Fuzzy Systems 10, 123-128, 2008.

14. J. Heizer and B. Render, Principles of Operations Management, McGraw-Hill, New Jersey, 2004.

15. W.J. Stevenson, Operations Management, McGraw-Hill, New York, 2005.

16. C.L.Hwang and K. Yoon, Multiple Attribute Decision Making, Springer-Verlag, Berlin, 1981.

17. C. Araz, P.M. Ozfirat, and I. Ozkarahan, An integrated multi-criteria decisionmaking methodology for outsourcing management, Computers \& Operations Research 34, 3738 -3756, 2007.

18. I. Ertuğrul and N. Karakaşoğlu, Performance evaluation of Turkish cement firms with fuzzy analytic hierarchy process and TOPSIS methods, Expert Systems with Applications 36, 702-715, 2009.

19. F.E. Boran, S. Genç, M. Kurt and D. Akay, A multi-criteria intuitionistic fuzzy group decision making for supplier selection with TOPSIS method, Expert Systems with Applications 36, 11363-11368, 2009.

20. K.T. Atanassov, Intuitionistic Fuzzy-Sets, Fuzzy Sets and Systems 20, 87-96, 1986.

21. L.A. Zadeh, Fuzzy sets, Information and Control 8, 338-353, 1965.

22. M.H. Shu, C.H. Cheng and J.R. Chang, Using intuitionistic fuzzy sets for faulttree analysis on printed circuit board assembly, Microelectronics Reliability 46, 2139-2148, 2006.

23. S. Genç, F.E. Boran and D. Akay, Some Approaches on Estimating Criteria Weights from Intuitionistic Fuzzy Preference Relations under Group DecisionMaking, Journal of Multiple-Valued Logic and Soft Computing inpress, 2010.

24. S. Genç, F.E. Boran, D. Akay and Z.S. Xu, Interval multiplicative transitivity for consistency, missing values and priority weights of interval fuzzy preference relations, Information Sciences 180, 4877-4891, 2010.

25. Z.S. Xu, Some similarity measures of intuitionistic fuzzy sets and their applications to multiple attribute decision making, Fuzzy Optimization and Decision Making 6, 109-121, 2007.

26. Z.S. $\mathrm{Xu}$ and J. Chen, An overview of distance and similarity measures of Intuitionistic Fuzzy Sets, International Journal of Uncertainty Fuzziness and Knowledge-Based Systems 16, 529-555, 2008.

27. Z.S. Xu and Q.L. Da, The uncertain OWA operator, International Journal of Intelligent Systems 17, 569-575, 2002. 